Technological University Dublin

DÜBLIN

ARROW@TU Dublin

2015

\title{
Binding of DNA by a dinitro-diester calix[4]arene: denaturation and condensation of DNA
}

\author{
Mary Deasy \\ Technological University Dublin, mary.deasy@tudublin.ie \\ Pilar Lopez-Cornejo \\ University of Seville, pcornejo@us.es \\ F J. Ostos \\ University of Seville
}

See next page for additional authors

Follow this and additional works at: https://arrow.tudublin.ie/ittsciart

Part of the Pharmacy and Pharmaceutical Sciences Commons

\section{Recommended Citation}

Deasy, M., Lopez-Cornejo. \& Ostos, F.J. (2015). Binding of DNA by a dinitro-diester calix[4]arene: denaturation and condensation of DNA. Colloids Surf B Biointerfaces, vol. 127, pg. 65-72. doi:10.1016/ j.colsurfb.2015.01.019.

This Article is brought to you for free and open access by the School of Science and Computing at ARROW@TU Dublin. It has been accepted for inclusion in Articles by an authorized administrator of ARROW@TU Dublin. For more information, please contact arrow.admin@tudublin.ie, aisling.coyne@tudublin.ie, gerard.connolly@tudublin.ie.

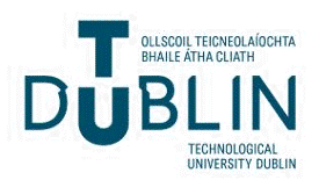




\section{Authors}

Mary Deasy, Pilar Lopez-Cornejo, F J. Ostos, J A. Lebron, and M L. Moya

This article is available at ARROW@TU Dublin: https://arrow.tudublin.ie/ittsciart/78 
BINDING OF DNA BY A DINITRO-DIESTER CALIX[4]ARENE: DENATURATION AND CONDENSATION OF DNA

\author{
F. J. Ostos ${ }^{1}$, J. A. Lebron ${ }^{1}$, M. L. Moyá ${ }^{1}$, M. Deasy ${ }^{2}$ and P. Lopez-Cornejo ${ }^{1, *}$ \\ ${ }^{1}$ Department of Physical Chemistry, Faculty of Chemistry, \\ University of Seville, c/ Prof. García González no 1, Sevilla 41012, Spain \\ ${ }^{2}$ Department of Science, Institute of Technology Tallaght (ITT Dublin), \\ Dublin 24, Ireland
}

*To whom all correspondence should be sent. Tel: +34-954557175 (ext. 215); Fax: +34-954557174; E-mail address: pcornejo@us.es 


\section{ABSTRACT}

A study of a dinitro-diester calix[4]arene (5,17-(3-nitrobenzylideneamino)-11,23di-tert-butyl- 25,27-diethoxycarbonyl methyleneoxy-26,28-dihydroxycalix[4]arene) interaction with calf-thymus DNA was carried out using several techniques. The measurements were done at various molar ratios $\mathrm{X}=[$ calixarene $] /[\mathrm{DNA}]$. Results show diverse changes in the DNA conformation depending on the $\mathrm{X}$ value. Thus, at low macrocycle concentration, the calixarene binds to the polynucleotide. This interaction, mainly in groove mode, weakens the hydrogen bonds between the base pairs of the helix inducing the denaturation of the double strands, as well as the condensation of the macromolecule, from an extended coil state to a globular state. An opposite effect is observed at X molar ratios higher than 0.07 . The de-condensation of DNA happens, that is, the transition from a compact state to a more extended conformation, probably due to the stacking of calixarene molecules in the solution. Results also show the importance of making a proper choice of the system under consideration.

KEYWORDS: Calixarene, DNA, denaturation, condensation, non-covalent interactions, gene therapy.

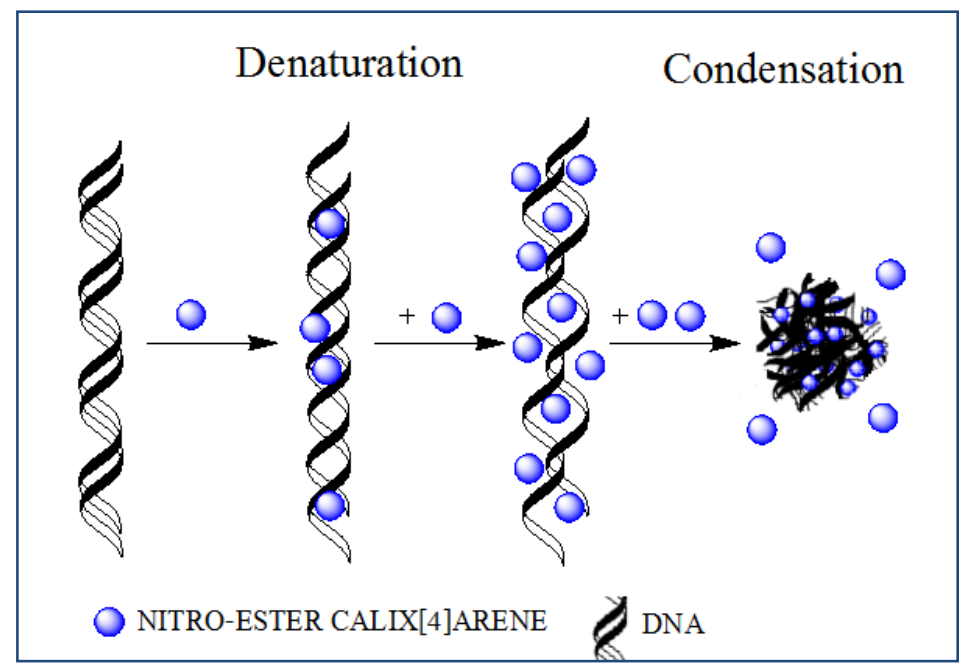




\section{INTRODUCTION}

DNA is a polyelectrolyte with a high negative charge. It has a double-stranded structure due to hydrogen bonds, $\Pi-\Pi$ and hydrophobic interactions between base pairs. The electrostatic interactions of cationic ions located on the nucleic acid surface with DNA phosphates provide stability to the structure [1]. Although the most stable conformation under physiological conditions is the B-DNA form, the adopted conformation depends on the presence in the medium of various agents such as alcohol [2,3], metal complexes [4], multivalent ions [5-9], positively charged polypeptides [1012], histones [13,14], polyamines [15] and nanoparticles [16,17]. Physico-chemical parameters such as salt concentration, solvent dielectric constant or temperature also induce conformational changes in the biomacromolecule's conformation [18].

A thorough understanding of the polynucleotide structure is important in relation to phenomena such as DNA transcription and replication [19] or with biomedical applications such as gene delivery and therapy [20].

Gene therapy is defined as the treatment of diseases by transfer of genetic material into cells. However, nucleic acids are large molecules with negative electric charge that cannot cross the cellular membrane per se. Thus, viral or non-viral vectors are necessary to reduce the size of the polynucleotide and transport it inside the cells. The reduction phenomenon of the size consists of a conformational change in DNA in which the polynucleotide acquires a more compact structure. This process is called compaction (or condensation).

The design of synthetic nanosystems able to transport nucleic acids to target cells is crucial. Systems such as cationic surfactants, nanoparticles, liposomes or nanotubes, all of them functionalized, have been used as vehicles (nonviral vectors) for gene delivery into cells [21-23]. 
Calixarenes are cyclic oligomers obtained from condensation reactions of aldehydes and phenols, resulting in cavities made of several phenolic units linked via methylene groups. They have hydrophobic cavities that can hold smaller molecules; but they also show a hydrophilic character when the benzenes that form the cavity are functionalized, either the upper rim or lower rim of the calixarene framework, with ionic groups. Therefore, they contain both hydrophobic and hydrophilic compartments together in the same molecule. Given their characteristics, they exhibit a great ability to be used as drug delivery systems. Compared to other cyclic systems, calixarenes have a peculiar characteristic with respect to their structure: they can adopt different conformations [24]. The number of conformations increases with the number of benzene units of the system, although this also depends on the solvent [25].

Several multivalent ligands can be attached to the calixarene framework with synthetic ease. Hence, different calixarene molecules can be synthesized to compact DNA. All of them were functionalized with cationic groups at the upper rim and with long hydrocarbon tails at the lower rim [26-29]. Results showed the binding was not fully based on purely electrostatic interactions. In this sense, binding via minor and/or major grooves of calixarenes with DNA also occurred [28].

Large calixarene dimers have also been used as suitable tools for cooperative DNA complexation. In most cases, a binding interaction by major grooves happens causing (or not) conformational changes in DNA. These changes depend on the structural characteristics of the macrocycle [30-32].

Here the authors have studied the interaction of a dinitro-diester calix[4]arene with calf-thymus DNA. The calixarene used has a terminal ester group at the lower rim and an aromatic ring at the upper rim that is able to bind with large complexes such as nucleic acids. Results show a strong interaction of the macrocycle with DNA that 
produces a partial denaturation and condensation of the polynucleotide, although no large hydrocarbon tail was added to the phenolic units.

\section{MATERIAL AND METHODS}

\section{Materials}

Sodium cacodylate and ethidium bromide were from Sigma-Aldrich. Calf thymus DNA sodium salt was purchased from Fluka and used without further purification. Polynucleotide concentration, given by phosphate groups, was determined spectrophotometrically from molar absortivity $\left(6600 \mathrm{~mol}^{-1} \mathrm{dm}^{3} \mathrm{~cm}^{-1}\right.$ at $\left.258 \mathrm{~nm}\right)$ [33]. An agarose gel electrophoresis test using ethidium bromide indicated that the average number of base pairs per DNA molecule is above 10000 bp [34]. The ratios in absorbance at 260 and $280 \mathrm{~nm}$ of the solutions were found to be between 1.8 and 1.9, which suggested the absence of proteins [35]. The dinitro-diester calix[4]arene (5,17-(3nitrobenzylideneamino)-11,23-di-tert-butyl- 25,27-diethoxycarbonyl methyleneoxy-26,28dihydroxycalix[4]arene, see Figure 1) used was synthesized as described previously [36]. This calixarene is poorly soluble in water, so it was diluted in a mixture of methanolwater at $20 \%(\mathrm{v} / \mathrm{v})$. All experiments were done at this methanol/water percent.

Methanol, nitrobenzene and ethyl acetate used were from Merck.

Some measurements were done with ssDNA to clarify results. For this purpose ssDNA stock solutions were prepared by thermal denaturalization of dsDNA following the procedure given in the literature [37].

All solutions were prepared with deionized water from a Millipore Milli-Q system, having a conductivity $<10^{-6} \mathrm{~S} \mathrm{~m}^{-1}$. The measurements were done at a fixed temperature of $298.2 \mathrm{~K}$ and at a fixed $\mathrm{pH}$ using a buffer solution ([cacodylate] $=0.01 \mathrm{~mol}$ $\left.\mathrm{dm}^{-3}, \mathrm{pH}=7\right)$. 


\title{
Methods
}

\begin{abstract}
Absorbance measurements
Absorbance spectra were obtained at different $\mathrm{X}(\mathrm{X}=[$ calixarene $] /[\mathrm{DNA}])$ values to prove the stability of the calixarene/DNA solutions using a CARY 500 SCAN UVvis-NIR spectrophotomer (Varian). Data were collected every $2 \mathrm{~nm}$ and the spectra were recorded in the wavelength range from 200 to $800 \mathrm{~nm}$. A standard quartz cell of 10 mm path length was used. The DNA concentration used was $2 \times 10^{-5} \mathrm{~mol} \mathrm{dm}{ }^{-3}$.
\end{abstract}

\section{Fluorescence measurements}

Intensity measurements were carried out using a Hitachi-f-2500 spectrofluorimeter interfaced to a PC for the recording and handling of the spectra. A standard quartz cell of $10 \mathrm{~mm}$ path length was used. Fluorescence titrations were performed at an ethidium bromide (EB) concentration of $2 \times 10^{-6} \mathrm{~mol} \mathrm{dm}^{-3}$. The concentration of DNA used was $2 \times 10^{-5} \mathrm{~mol} \mathrm{dm}^{-3}$. The quantity of the calixarene added to the solution depended on what was needed for the polynucleotide each time in order to study the whole range of the molar ratio $\mathrm{X}$ from 0 to 1 . The excitation and emission wavelengths were $480 \mathrm{~nm}$ and $593 \mathrm{~nm}$, the maximum wavelengths corresponding to EB.

\section{Circular dichroism spectra}

Electronic circular dichroism (CD) spectra were recorded in a Biologic Mos-450 spectropolarimeter. A standard quartz cell of $10 \mathrm{~mm}$ path length was used. Scans were taken from 220 to $320 \mathrm{~nm}$ for the intrinsic region. Each spectrum was obtained from an average of 10 runs at a fixed temperature of $298.2 \mathrm{~K}$ with a 5 min equilibration before each scan. The spectra obtained were expressed in terms of molar ellipticity. 
Spectra were obtained at a fixed DNA concentration and in the presence of varying amounts of calixarene in order to obtain the appropriate molar ratio $\mathrm{X}$ $(\mathrm{X}=[$ calixarene $] /[\mathrm{DNA}]$.

\section{Viscosity measurements}

Viscosity measurements were carried out using an Ostwald microviscometer immersed in a thermostated water bath at a temperature of $298.2 \pm 0.1 \mathrm{~K}$. The viscometer was calibrated with water and methanol. The measurements were repeated at least ten times.

The viscosity behaviour of the DNA-calixarene solutions was characterized through the relative viscosity $\eta_{\mathrm{r}}$, defined as $\eta / \eta_{\mathrm{o}}$, that is, the ratio between the viscosity of the suspension and the viscosity of the pure solvent (methanol/water at $\mathrm{pH}=7$ with a sodium cacodylate buffer).

Information about structural changes in the polynucleotide is obtained from the relative viscosity, $\eta_{\mathrm{r}}$, changes relataive to the molar ratio $\mathrm{X}=[$ calixarene]/[DNA]

\section{Melting measurements}

The thermal denaturalization study was performed on a Biologic spectrophotometer equipped with a Peltier temperature controller. The apparatus has a temperature program to control the speed of temperature change during the experiments. The rise in temperature was $0.2^{\circ} \mathrm{C} \mathrm{min}^{-1}$. The recording chart reads temperature and absorbance differences between the reference and the sample cuvettes at $258 \mathrm{~nm}$.

All melting measurements were done at a fixed DNA concentration of $1.2 \times 10^{-5}$ mol dm ${ }^{-3}$. 


\section{AFM measurements}

The images were obtained with a Molecular Imaging PicoPlus 2500 AFM (Agilent Technologies). Silicon cantilevers (Model Pointprobe, Nanoworld) with a resonance frequency of around $240 \mathrm{KHz}$ and nominal force constant of $42 \mathrm{~N} / \mathrm{m}$ were used. All AFM imaging was recorded in air and in the tapping mode, with scan speeds of about $0.5 \mathrm{~Hz}$, with data collection at 256 x 256 pixels.

In order to image isolated DNA molecules, it was necessary to use dilute solutions $\left(0.3 \mu \mathrm{mol} \mathrm{dm}{ }^{-3}\right)$ due to the large size of these molecules. AFM images of the calixarene/DNA complexes were obtained by drying a $30 \mu \mathrm{L}$ droplet of calixarene and DNA solution previously deposited on modified mica. The modified mica surface was prepared dropping a $0.1 \%(\mathrm{v} / \mathrm{v})$ APTES aqueous solution onto a freshly cleaved mica surface. After 20 minutes, the surface was washed with ultra-pure water and air dried. A total of $30 \mu \mathrm{L}$ of DNA (or calixarene/DNA) solution was dropped onto this modified surface, incubated for 30 min, washed with pure water and air dried for AFM imaging.

\section{RESULTS}

\section{Absorbance measurements}

Figure I in Supplementary Data shows the stability of the calixarene/DNA solution (measured at $258 \mathrm{~nm}$ ) for $X=0.01$. As can be seen, a high stability of these solutions was maintained for the range of concentrations used in this work.

\section{Fluorescence measurements}

Ethydium bromide (EB) is a planar fluorescence probe which spontaneously binds to DNA [38]. Here we have studied the fluorescence emission of EB in the 
presence of DNA and calixarene. Figure 2 shows the results obtained: a first decrease of the fluorescence emission for $\mathrm{EB}$ when the calixarene concentration increases from $\mathrm{X}=0$ to $\mathrm{X}=0.075$, and a further increase of the emission intensity for $\mathrm{EB}$ for the highest calixarene concentrations $(X>0.075)$. The inserted Figure (within Figure 2) shows EB fluorescence in the presence of different quantities of calixarene and with the absence of polynucleotide. The emission intensity of EB showed minimal change in the absence of DNA. Calixarene concentrations used in the absence of DNA were the same as those used in the presence of the polynucleotide in the range of $\mathrm{X}$ from 0 to 1 . Experiments using $\mathrm{X}$ values higher than 1 could not be carried out due to solubility problems with the calixarene.

\section{Circular dichroism measurements}

CD spectra were obtained on DNA solutions at fixed concentrations in the presence of different amounts of the dinitro-diester calixarene, to determine conformational changes possible upon binding of such species to DNA.

DNA in aqueous solution adopts a right-handed $\mathrm{B}$ conformation, which shows a characteristic CD spectrum in the far UV region $(220-320 \mathrm{~nm})$. The spectrum displayed a positive peak at approximately $278 \mathrm{~nm}$ and a negative peak at $247 \mathrm{~nm}$. These bands are caused by stacking interactions between bases and by the helical suprastructure of the polynucleotide that provides an asymmetric environment for the bases [39]. Structural alterations of the DNA, caused by its interaction with different ligands, produce changes in this intrinsic CD spectrum [40-42].

Additional measurements were done to prove if the CD spectrum of DNA in the mixture $\mathrm{MeOH} /$ water at $20 \% \mathrm{v} / \mathrm{v}$ (the solvent used in this work) showed differences with the spectrum obtained in pure water. Results showed the same peaks and crossover 
points were the same as those obtained for the DNA in pure water. Changes in the spectrum, and therefore in the conformation, were only obtained at methanol percentages $\geq 50 \%$ v/v (see Figure III in Supplementary Data).

A peculiar behaviour in the molar ellipticity values corresponding to the maximum intensity of the negative $(245 \mathrm{~nm})$ and positive $(278 \mathrm{~nm})$ bands was observed when $\mathrm{X}$ was changed. With the addition of different quantities of calixarene, at a fixed polymer concentration, the molar ellipticity of the positive and negative bands decreased in the $\mathrm{X}$ range between 0 and 0.07 . On the other hand, an increase in the ellipticity was witnessed for $\mathrm{X}$ values higher than, approximately, 0.07. The intensities of the two bands, $278 \mathrm{~nm}(\mathrm{~A})$ and $245 \mathrm{~nm}(\mathrm{~B})$, are reported in Figure 3 as a function of the molar ratio $\mathrm{X}$ at different calixarene concentrations. Although the overall contour of the spectrum was maintained in the whole range of $\mathrm{X}$ values studied, the bands showed a bathochromic shift of about $4 \mathrm{~nm}$ (Figure 4).

\section{Viscosity measurements}

Macroscopic properties of microheterogeneous systems can be easily obtained from viscosity data [43]. With respect to DNA solutions, binding modes of a ligand with the polynucleotide can be distinguished from this type of measurement. Intercalation provokes an increase of the DNA length which results in an increase of the viscosity. On the contrary, groove binders do not increase the length of the polynucleotide catalysing a decrease in viscosity or a constant value [44].

Figure 5A shows the dependence of the relative viscosity with the molar ratio X. As can be seen, the viscosity increased when small quantities of calixarenes are added to the DNA solution. After a determined $\mathrm{X}$ value, the viscosity decreased for higher calixarene concentrations at a fixed DNA concentration. The maximum of this trend 
happened at an $\mathrm{X}$ value of $\sim 0.07$. Figure $5 \mathrm{~B}$ collects the variation that the relative viscosity showed for single-stranded DNA solutions in the presence of different quantities of calixarene. Figure II in Supplementary Data shows the stability of an ssDNA solution.

\section{Melting measurements}

Thermal denaturation behaviour of DNA solutions in the presence of different concentrations of calixarene offers information about conformational changes in the polynucleotide as well as providing information on the strength and the character of the DNA/calixarene interaction. Figure 6A in the text and Figure IV in Suplementary Data show the melting curves obtained at different $\mathrm{X}$ values.

The melting temperature was determined as the average of the initial and final temperatures of the melting process. The profiles were almost linear in the melting region studied. The results show two different trends: a first $T_{m}$ decrease by increasing the value of the molar ratio $\mathrm{X}$, and a further increase for higher [calixarene]/[DNA] ratios (see Figure 6B). The minimum of this trend was seen at an $\mathrm{X}$ value of about 0.065 .

\section{AFM experiments}

Different structures were observed depending on the concentration ratio calixarene/DNA. Figure VA in Supplementary Data shows AFM topographic image of double stranded DNA, adsorbed onto an APTES modified mica surface, in an extended coil conformation in the absence of calixarene. Morphological changes from an elongated coil state to a more compact globular structure were observed when the calixarene was added to the DNA solution. Polynucleotide molecules with loops, as 
well as few globules, are seen in Figures 7A and V A-C (in Supplementary Data). The images show that the loops appear to be mainly intramolecular, although intermolecular loops are also a possibility.

At higher $X$ values, $X>0.1$ the early stages of a de-condensation event seem to appear: the DNA molecule is less compacted, that is, an unwinding of the globules of DNA happens (Figure 7B). This process may happen due to the assembly among calixarene molecules in solution.

\section{DISCUSSION}

Emission spectroscopy is a technique used to glean information about the binding mode of different species with DNA. In general, the interaction of a fluorescence compound with DNA provokes changes in its emission spectrum [45].

In this regard, the intercalative character of the dye ethydium bromide is well known. Its emission intensity increases in DNA solutions due to the intercalation of the planar aromatic rings between the base pairs of the double helical DNA [46]. Changes in its emission intensity are due to changes in its binding mode to the polynucleotide. So, a decrease in the emission intensity of EB in DNA solutions is interpreted by the authors as a displacement of the probe from the intercalative position between the base pairs of the DNA molecules to the aqueous solution [47].

When the dinitro-diester calixarene is added to a DNA/EB solution a sharp decrease of the emission intensity is observed. The emission intensity of the dye increases with the $\mathrm{X}$ molar ratio after a specific calixarene concentration, that is, at higher calixarene concentrations. No shift of the band wavelength is observed. The fluorescence results are based on the idea that a simple binding mode of the macrocycle with the polynucleotide does not happen. At first, the decrease seems to be due to a 
possible intercalation of the calixarene into the stacked base pairs of the DNA: the dye has moved from a nonpolar environment to a more polar medium, the aqueous solution, due to the possible intercalation of the calixarene. However, from results presented later, melting measurements demonstrate that only a partial intercalation of the macrocycle with the polynucleotide occurs.

The increase in the emission intensity observed for the higher $\mathrm{X}$ values is due to a change in the binding mode of the calixarene. It is known that the interaction of EB with DNA is mainly intercalative, although Bresloff et al. demonstrated that about a $20 \%$ of the dye interacts with the polynucleotide in the groove mode [46]. If a structural change (compaction) in DNA takes place at the higher $\mathrm{X}$ values, the polarity of the environment where the $\mathrm{EB}$ is located will diminish and the emission intensity will increase. This is what was observed. The dinitro-diester calixarene used here does not interact with $\mathrm{EB}$ or, at least, the emission spectrum of the dye does not change in the presence of calixarene (see Figure 2). To clarify the binding mode of the macrocycle with DNA at the different $\mathrm{X}$ values, $\mathrm{CD}$ spectra and melting measurements were done.

As mentioned above, circular dichroism (CD) is a technique used for monitoring structural changes in nucleic acid conformation. Thus, the CD spectrum of DNA was run at different $\mathrm{X}$ values. Upon addition of different calixarene quantities, at a fixed polymer concentration, the molar ellipticity of the positive and negative bands of DNA decreased in the $X$ range between 0 and 0.07 . A change in the molar ellipticity was observed at the higher molar ratio (see Figure 3). Again, as witnessed with the fluorescence measurements, the trend in the intrinsic CD spectrum showed a different binding of the calixarene with different $\mathrm{X}$ values. In addition to the changes in the intensity of the band, a bathochromic effect of the spectrum $(\sim 4 \mathrm{~nm})$ was observed for lower X values (see crossover point in Figure 4). The maximum shift was obtained at an 
$\mathrm{X}$ value of $\sim 0.07$. The spectrum did not change for higher calixarene concentrations (that is, for higher $\mathrm{X}$ values).

The movement of the spectrum's wavelength to red could be related to a denaturation of the polynucleotide, that is, the double-helix molecules are separated in single-stranded DNA molecules [37]. The binding of the calixarene to the polynucleotide provokes a destabilization of the two strands. Bearing in mind that the strands of DNA are held together by hydrogen bonds between the complementary base pairs, the interaction of the dinitro-diester calixarene seems to induce hydrogen bond breaking between the base pairs. The variation observed in the intensity of may be due to a change in the configuration of DNA chains.

The destabilization of the double-helix in the presence of calixarene was also proven from viscosity and melting measurements. The viscosity values of calixarene/DNA solutions showed a sharp increase with the quantity of the macrocycle in the medium in the range of $\mathrm{X}$ from 0 to 0.07 . A further decrease was also observed for higher $\mathrm{X}$ values. Intercalation is known to provoke an increase of the viscosity, due to an increase of the DNA length, while groove binders induce constancy or a decrease of this parameter [48].

An increase in viscosity may also be due to a denaturation of the doublestranded DNA which dissociates to single strands. To prove this point, the viscosity of single-stranded DNA solutions was measured in the presence of calixarene. In this case a constant viscosity was observed in the range of $\mathrm{X}$ from 0 to 0.07 . A decrease in the relative viscosity was obtained when the concentration of calixarene was increased. Therefore, this result confirms that a denaturation of the polynucleotide happens when the dinitro-diester calixarene is added to the solution (melting experiments also confirm this result as discussed later). 
The decrease in viscosity obtained (with dsDNA and ssDNA) when the calixarene quantity increases is most likely due to a configurational change of DNA (see below).

The denaturation effect that the dinitro-diester calixarene produces on DNA was also confirmed from melting measurements. An initial decrease in the melting temperature was observed in the $\mathrm{X}$ range from 0 to 0.07 and an increase was seen for higher calixarene concentrations. Again two trends were apparent, depending on the molar ratio [calixarene]/[DNA], and the change is collected at the same $\mathrm{X}$ value of 0.07 .

It is known that intercalation provokes a lengthening and a stiffening effect on the DNA duplex, showing disruption of stacking constants of the bases and a stabilization of the right-handed B form of the calf-thymus DNA [49]. If the increase observed in the viscosity measurements was due to the intercalation of the calixarene into the DNA, an increase of the melting temperature would have been observed due to this stabilization phenomenon. On the contrary, a decrease in the temperature melting happened when calixarene was added to a DNA solution, that is, the dinitro-diester calixarene interacts with DNA provoking the breaking of the hydrogen bounds between base pairs and, therefore, a destabilization of the double helix. This type of behaviour has been previously observed for other compounds. So, for example, $\mathrm{Cu}^{2+}$ ions induce hydrogen bond breaking between guanine and cytosine, giving rise to a destabilization of the double helix [50]. Other ions such as $\mathrm{Zn}^{2+}, \mathrm{Mn}^{2+}, \mathrm{Ni}^{2+}$, and $\mathrm{Co}^{2+}$ also produce the destabilization of the double-stranded DNA at high concentrations [51].

The decrease in the melting temperature obtained for $\mathrm{X}$ values higher than 0.07 seems to match the decrease in viscosity data, that is, a change in the DNA configuration happens when more calixarene is added to the solution. Supian et al. found aggregates of this type of calixarene in the solid state, that is, the molecules were 
stacked one inside the other [36]. Bearing this in mind, supramolecular aggregates among calixarenes molecules could also be formed in solution (see Figure 8). If this happens, the formation of large aggregates will be favoured at the higher macrocycle concentrations. Therefore, the behaviour observed from different techniques at $\mathrm{X}$ values higher than 0.07 could be due to the formation of aggregates: an increase in the number of calixarene molecules in the solution favours the stacking among them. If this stacking arrangement stabilizes the calixarene molecules in the aqueous solution, the addition of more calixarene to the medium could weaken the interaction of calixarene/DNA. In this case, the polynucleotide would adopt a new conformation more similar to that corresponding to its original situation.

Based on the results above, the dinitro-diester calixarene appears to interact with DNA provoking changes in the DNA configuration. Therefore, at the lowest $\mathrm{X}$ values, the calixarene binding with DNA weakens the hydrogen bonds between the pair bases of the polynucleotide separating the two strands, inducing partial DNA denaturation (of course it is expected that a mixture of single and double-stranded DNA will be present in the solution).

The hydrophobic groups of the polynucleotide in dsDNA are largely hidden, whereas they are exposed to the solution in the case of ssDNA. Thus, the hydrophobic interactions in the presence of single strands will increase and also the compaction of DNA will be favoured, that is, DNA will adopt a more globular conformation. The latter has been postulated based on the results of Dias et al [52]. These authors studied the interaction of DNA with different cationic surfactants. Results showed a lower critical aggregation concentration (cac) for single-stranded DNA than for dsDNA. In general, the compaction of the polynucleotide was more favoured in ssDNA. Bearing this in mind, it is expected that DNA will go from an extended (coil) state to a more compact (globular) conformation in the presence of the dinitro-diester calixarene. 
With regard to the binding mode of calixarene to DNA, it is known that nitrobenzene (and its derivatives) interacts with DNA by intercalatation between the base pairs of the poynucleotide [53,54]. Therefore, one can expect that the dinitro-diester calixarene intercalates into the DNA by the nitrobenzene group. Intercalation is driven by large favourable enthalpy contributions and is opposed by entropy. As was mentioned above, intercalation results in both lengthening and stiffening of the DNA duplex which stabilizes the double chain [50]. Results obtained from the melting denaturation technique showed a fall in the melting temperature at the lower $\mathrm{X}$ values. Based on this, the dinitrodiester calixarene does not interact with DNA by intercalation. The interaction will mainly take place by groove mode, besides producing the compaction of the polynucleotide as was discussed above. In any case, the authors do not discard the possibility of a partial intercalation of the dinitro-diester calixarene with DNA that does not produce the typical stabilization of the double strands.

After reaching a molar ratio [calixarene]/[DNA] value of about 0.07 , the trends observed from the different techniques used in the present work, when more calixarene was added to the solution, can be summarized as follows: a conformational change in the polynucleotide from a compact (globule) state to a more elongated (coil) conformation happens which is produced by the formation of supramolecular structures of calixarene molecules.

Going further, more information was obtained from melting measurements: it is known that the melting transition of DNA is highly cooperative $\left(\Delta \mathrm{T} \approx 10-15^{\circ} \mathrm{C}\right.$, see Figures 6A and III A-E, in S.D.). However, a less cooperative trend is obtained for $\mathrm{X}=0.04$ and $0.065\left(\Delta \mathrm{T} \approx 30^{\circ} \mathrm{C}\right.$, see Figures IIIB, in S.D., and 6A). A less cooperative transition can be due to unfolding of the duplex. This result confirms our finding.

More information was obtained from the atomic force microscopy technique (AFM) in order to clarify and prove these changes on DNA conformation. 
The results show that conformational changes in DNA do indeed take place in the presence of the calixarene. Different structures were observed depending on the $\mathrm{X}$ value. At low calixarene concentration, the macrocycle interacts with the polynucleotide inducing denaturation and an increase in the bending of the DNA molecule. This increase results in a decrease of the apparent persistence length, which leads to the formation and stabilization of intramolecular loops (see Figures 7A and IV B-C -in S.D.). This stabilization happens by the formation of flower-like structures and disks, which is considered by Fang and Hoh [55] as a type of DNA strand-strand stabilization. The partial denaturation of the double-stranded DNA, induced by the dinitro-diester calixarene, leaves hydrophobic groups of the polynucleotide exposed to the aqueous solution. The reorganization of the water located between macromolecular surfaces can also favour this stabilization [56].

At $\mathrm{X}$ values higher than 0.07 a structural change of the polynucleotide from a more (partial) compact state to a more extended structure in observed, that is, a decondensation process befalls as Figure 7B shows. The compact structures are also seen to be more separated, perhaps due to loss of loops. Pearling-ring structures appear. This new arrangement of the polynucleotide may be due to the stacking of calixarene molecules in the solution, as it is shown in Figure 8, which weakens the globular conformation of DNA.

The formation of supramolecular structures among the calixarenes has been proved from fluorescence measurements. The dinitro-diester calixarene shows a (small) emission band in solution with a maximum wavelength centred at $420 \mathrm{~nm}$ when the molecule is excited at $367 \mathrm{~nm}$. Bearing this in mind, the emission spectrum was registered in a water/MeOH solution $(20 \%$ water/MeOH v/v, $\mathrm{pH}=7 \quad 0.01 \mathrm{M}$ with cacodylate) at different macrocycle concentrations. Results are shown in Figure VI in 
Supplementary Data. The emission intensity increased in a linear fashion when the calixarene concentration increased and, after a specific concentration, a change in the slope of the plot EI versus $\log$ [calixarene] was obtained. This modification in the emission intensity is clearly due to the formation of supramolecular structures among the different macrocycles, as was proposed originally.

The results obtained here have been compared with other results previously observed by our group using cationic surfactants as vectors to condense DNA [57, 58]. Cationic surfactants such as CTAB or gemini surfactants $\left(12-2-12,2 \mathrm{Br}^{-}\right.$and $12-10$ $12,2 \mathrm{Br}^{-}$) provoke the condensation of the polynucleotide due to ion correlation effects, generated by the formation of micellar aggregates on the polymer surface. The electrostatic interaction between the cationic surfactant head and the phosphate groups of the DNA backbone, as well as the hydrophobic interactions among the hydrocarbon chains of the surfactant located at the polynucleotide surface, indicate the compaction of the polymer. After a specific surfactant concentration, a breakdown of the condensed DNA also seemed to happen due to the formation of micelles in the solution. The dinitro-diester calixarene also induces the condensation of the polynucleotide. However, the bound mode is different. In fact, prior to the conformational change in DNA, the calixarene interacts with the polynucleotide by a groove mode inducing hydrogen bond breaking between the base pairs and, thus, the partial denaturation of the double strands. This fact favours the condensation process. As happened with the surfactants, after a specific calixarene concentration, a de-compaction of the polynucleotide takes place. The formation of supramolecular structures among the macrocycle molecules in solution stimulates the disruption of the DNA globules.

In conclusion, the dinitro-diester calix[4]arene used interacts with calf-thymus DNA generating different conformational changes. Initially the macrocycle binds to the 
polynucleotide by groove mode inducing a partial denaturation of the double chains. The interaction, favoured by the breakup of the double helix, resulting in the compaction of the DNA: the macromolecule goes from an elongated (coil) form to a more compact (globule) state. The addition to a higher calixarene concentration (X > 0.07) produces the de-condensation of the macromolecule probably due to the formation of supramolecular assemblies in which a macrocycle is stacked inside the other.

Due to significance of this phenomenon in gene transfection processes, other authors have designed several funcionalized calixarenes with long hydrophobic tails to induce such condensation of DNA molecules [26-29]. It has been demonstrated here the importance of adequately choosing the study system to get the desired goal.

It is worth noting that calixarenes have cavities able to accommodate different molecules inside. Accordingly, they can be used as drug and/or gene delivery systems. This fact increases the interest for using calixarenes as non-viral vectors in processes of gene transfection.

\section{ACKNOWLEDGMENTS}

This work was financed by the Consejería de Innovación, Ciencia y Empresa de la Junta de Andalucía (P08-FQM-03623 and P12-FQM-1105) and the European Union (Fondos Feder). The authors thank to Dr. F. Kelleher and to Dr. J. P. Ward for their contributions in the synthesis of the nitro-ester calix[4]arene used. 


\section{BIBLIOGRAPHY}

[1] R. S. Dias and B. Lindman, in DNA interactions with polymers and surfactants. New Jersey: Wiley and Sons; 2008, pp.2 and ff.

[2] J. C. Girod, W. C. J. Johson, S. K. Huntington, and M.F. Maestre, Biochemistry, 12 (1983) 5092-5096.

[3] R. Huey and S.C. Mohr, S. C, Biopolymers 20 (1981) 2533-2552.

[4] (a) X. Meng, L. Liu, C. Zhou, L. Wang and C. Liu, Inorg. Chem 47 (2008) 65726574. (b) I. Haq, P. Lincoln, D. Suh, B. Norden, B. Chowdhry and J. Chaires J. Am. Chem. Soc. 117 (1995], 4788-4796.

[5] R. W. Wilson and V. A. Bloomfield, Biochemistr 18 ( 1979) 2192-2196.

[6] C. Ma and V.A. Bloomfield, Biophys. J. 67 (1994) 1678-1681.

[7] K. Besteman, K. van Eijk, and S.G. Lemay, Nature Physics 3 (2007) 641-644.

[8] F. Jiménez-Ángeles and M.A. Lozada Cassou, J Phys. Chem. B 108 (2004) 72867296.

[9] J. Lyklema, Colloids and Surface A: Physicochem. Eng. Aspects 291(2006) 3-12.

[10] P. Cohen and C. Kidson, J. Mol. Biol. 35 (1968) 241-245.

[11] J. T. Shapiro, M. Leng, and G. Felsenfeld, Biochemistry 8 (1969) 3219-3232.

[12] M. Suwalsky and W.A. Traub, Biopolymers 11 (1972) 2223-2231.

[13] G.D. Fasman, B. Schaffhausen, L. Goldsmith and A. Adler, Biochemistry 9 (1970) 2814-2822.

[14] A.J. Adler, E.C. Moran and G. D. Fasman, Biochemistry 14 (1975) 4179-4185.

[15] L.C. Gosule and J.A. Schellamn, Nature 259 (1976) 333-335.

[16] A.A. Zinchenko, T. Sakaue, S. Aaraki, K. Yoshikawa, D. Baigl., J. Phys. Chem. B. 111 (2007), 3019-3031. 
[17] C.-L. Feng, X.-Q. Dou, Q.-L. Liu, W. Zhang, J.-J. Gu, S.-M. Zhu, A. T. A. Jenkins and D. Zhang, Sensors 13 (2013) 5749-5756.

[18] A. Estévez-Torres and D. Baigl, Soft Matter, 2011, 7, 6746-6756.

[19] B.L: Kankia, V. Buckin, V.A. Bloomfield, Nucleic. Acid. Res 29 (2001) 27952801.

[20] D.V. Schaffer and W. Zhou, Gene Therapy and Gene Delivery Systems. Adv. Biochem. Engin./Biotech. Vol. 99. T. Scheper, ed. Springer-Verlag: Berlin, 2005.

[21] C. Wang, S.D. Wettig, M. Foldvari, R.E. Verrall, Langmuir 23 (2007) 8995-9001.

[22] M. Rosa, N. Penacho, S. Simoes, M.C.P. Lima, B. Lindman, M.G. Miguel, Mol. Membrane Biol.25 ( 2008) 23-34.

[23] X. Guo, L. Huang, L. Acc. Chem., 45 (2012) 971-979.

[24] S. Shinkai, K. Araki, H. Koreishi, T. Tsubaki, O. Manabe, Chem. Lett., 1986, $1351-1354$.

[25] F. Perret, V. Bonnard, O. Danylyuk, K. Suwinska, and A. W. Coleman, New. J. Chem.30 (2006) 987-990.

[26] F. Sansone, M. Dudic , G. Donofrio, C. Rivetti, L. Baldini, A. Casnati, S. Cellai and R. Ungaro, J. Am. Chem. Soc. 128 (2006) 14528-14536.

[27] P. Shahgaldian, M.A. Sciotti and U. Pieles, Langmuir 24 (2008) 8522-8526.

[28] V. Rullaud, M. Siragusa, A. Cumbo, D. Gysax, and P. Shahgaldian, Chem. Commun. 48 (2012) 12186-12188.

[29] S. B. Nimse and T. Kim, Chem. Soc. Rev. 42 (2013) 366-386.

[30] R. Zadmard and T. Schrader, Angew. Chem. Int. 45 (2006) 2703-2706.

[31] C. J. Blecking, W. Hu, R. Zadmard, A. Dasgupta and T. A. Schrader, Synthesis 8 (2011) 1193-1204.

[32] M. Li, M. S. Peters and T. Schrader, Natural Product Comm. 7 (2011) 409-417. 
[33] Y. J. Liu, H. Chao, L. F. Tan, Y. X. Yuan and L. N. Ji, Inorg. Chim. Acta 358 (2005) 1904-1910.

[34] F. Secco, M. Venturini, T. Biver, F. Sanchez, R. Prado-Gotor and E. Grueso, J. Phys. Chem. B 114 (2010) 4686-4691.

[35] W. Saenger, in Principles of Nucleic Structure; Springer-Verlag: New York; 1984.

[36] F. L. Supian, T.H. Richardson, M. Deasy, F. Kelleher, J.P. Ward, V. McKee, Sains Malays. 39 (2010) 423-433.

[37] M. Rosa, R. Dias, M.G. Miguel and B. Lindman, Biomacromolecules 6 (2005) 2164-2171.

[38] J.R. Lakowicz, in Principles of Fluorescence Spectroscopy. 2nd edition. New York: Kluwer Academic/ Plenum Publishers; 1999, pp. 76-77, 605.

[39] S. Neidle, in Nucleic Acid Structure and Recognition. New York: Oxford University Press; 2002, pp.89-138.

[40] P. Lincoln, A. Broo and B. Norden, J. Am. Chem. Soc. 118 (1996) 2644-2653.

[41] N.C. Garbett, P.A. Ragazzon and J. B. Chaires, Nature Protocols 2 (2007) 3166 3172.

[42] N. Berova, K. Nakanishi and R.W. Woody, in Circular Dichroism: Principles and Applications. 2nd ed. New York: Wiley-VCH; 2000, pp. 741-768.

[43] D. Suh and J.B. Chaires, Bioorg. Med. Chem. 3 (1995) 723-728.

[44] S. Marchetti, G. Onori and C. Cametti, J. Phys. Chem. B 109 (2005) 3676-3680.

[45] M. Rahban, A. Divsalar, A.A. Saboury and A. Golestani, A., J. Phys. Chem. C, 114 (2010) 5798-5803.

[46] J.L. Bresloff and D. M. Crothers, J. Mol. Biol. 95 (1975) 103-123.

[47] A. Dasgupta, P. K. Das, R. S. Dias, M. G. Miguel, B. Lindman, V. M. Jadhav, M. Gnanamani and S. Maiti, J. Phys. Chem. B 111 (2007) 8502-8506. 
[48] (a) D. Suh and J. B. Chaires, Bioorg. Med. Chem. 3 (1995) 723-728. (b) A. M. Burger, T. C. Jenkins, J. A. Double and M. C. Bibby, British J. Cancer 81 (1999) 367375. (c) M. R. Beccia, T. Biver, A. Pardini, J. Spinelli, F. Secco, M. Venturini, N. Busto-Vazquez, M. P. Lopez-Cornejo, V. Martin-Herrera and R. Prado-Gotor, Chem. Asian J. 7 (2012) 1729-1737. (d) E. Grueso, P. Perez-Tejeda, R. Prado-Gotor and C.Cerrillos, J. Phys. Chem. C 118 (2014) 4416-4428. f) N. W. Luedtke, J. S. Hwang, E. Nava, D. Gut1, M. Kol1 and Y. Tor, Nucleic Acids Res. 31 (2003) 5732-5740.

[49] J. B. Chaires, Arch. of Biochem. Biophys. 453 (2006) 26-31.

[50] H. Richard, J. P. Schreiber and M. P. Daune, Biopolymers 12 (1973) 1-10.

[51] G. L. Eichhorn and Y. A. Shin, J. Am. Chem. Soc. 90 (1968) 7323-7328.

[52] R. S. Dias, L. M. Magno, A. J. M. Valente, D. Das, P. K. Das, S. Maiti, M. G. Miguel and B. Lindman, J. Phys. Chem. B, 112 (2008) 14446-14452.

[53] F. Passero, E. J. Gabbay, B. Gaffney and T. Kurucsev, Macromolecules 3 (1970) 158-162.

[54] S.-J. Hong, L. H. Piette, Arch. Biochem. Biophys. 185 (1978) 307-315.

[55] Y. Fang and J. H. Hoh, J. Am. Chem. Soc. 120 (1998) 8903-8909.

[56] D. C. Rau and V. A. Parsegian, Biophys. J. 61 (1992) 246-271.

[57] E. Grueso, C. Cerrillos, J. Hidalgo and P. Lopez-Cornejo, Langmuir 28 (2012) 10968-10979.

[58] J. P. García, E. Marrón, V.I. Martín, M.L. Moyá and P. Lopez-Cornejo, Colloids and Surfaces B:Biointerfaces 118 (2014) 90-100. 


\section{Figure Legends}

Figure 1: Schematic representation of the dinitro-diester calix[4]arene.

Figure 2: Plot of $\mathrm{I} / \mathrm{I}_{\mathrm{o}}$ of ethydium bromide in calixarene/DNA solutions versus the molar ratio $\mathrm{X}\left([\mathrm{DNA}]=2 \times 10^{-5} \mathrm{~mol} \mathrm{dm}^{-3}\right)$. Figure inserted shows the relative emission intensity of ethydium bromide in the presence of different calixarene concentrations and absence of DNA. Error bars represent standard deviations in each $\mathrm{X}$ value $(n=5)$.

Figure 3: Dependence of the molar ellipticity of the positive (A) and negative (B) bands on the $\mathrm{X}$ molar ratio at different calixarene concentrations $\left([\mathrm{DNA}]=2 \times 10^{-5} \mathrm{~mol}\right.$ $\left.\mathrm{dm}^{-3}\right)$

Figure 4: $C D$ spectrum of DNA at different $X$ values. The insert shows the shift of the crossover point with the $\mathrm{X}$ molar ratio $\left([\mathrm{DNA}]=2 \times 10^{-5} \mathrm{~mol} \mathrm{dm}^{-3}\right)$.

Figure 5: Relative viscosity of calixarene/dsDNA (A) and calixarene/ssDNA (B) solutions at different $\mathrm{X}$ values. Error bars represent standard deviations in each $\mathrm{X}$ value $(\mathrm{n}=10)\left([\mathrm{DNA}]=2 \times 10^{-5} \mathrm{~mol} \mathrm{dm}^{-3}\right)$.

Figure 6: (A) Melting curve obtained at $X=0.065$. (B) Melting temperature values obtained at different $\mathrm{X}$ values. Error bars represent standard deviations in each $\mathrm{X}$ value $(\mathrm{n}=3)\left([\mathrm{DNA}]=1.2 \times 10^{-5} \mathrm{~mol} \mathrm{dm}^{-3}\right)$

Figure 7: AFM topographic image of calf thymus DNA adsorbed on APTES-modified mica surface in the presence of calixarene $(A X=0.06$ and $B X=0.35,[D N A]=0,3 \mu \mathrm{mol}$ $\left(m^{-3}\right)$.

Figure 8: Stacking arrangement of nitro-ester calixarene molecules. 
Figure 1

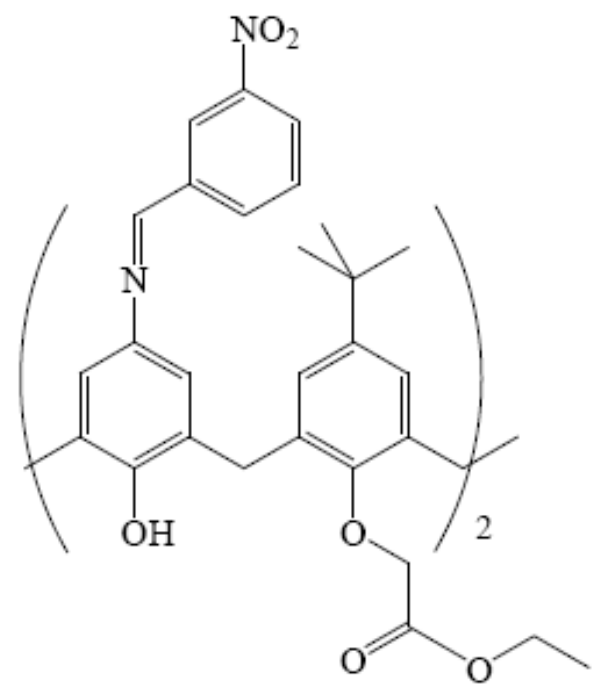

Figure 2:

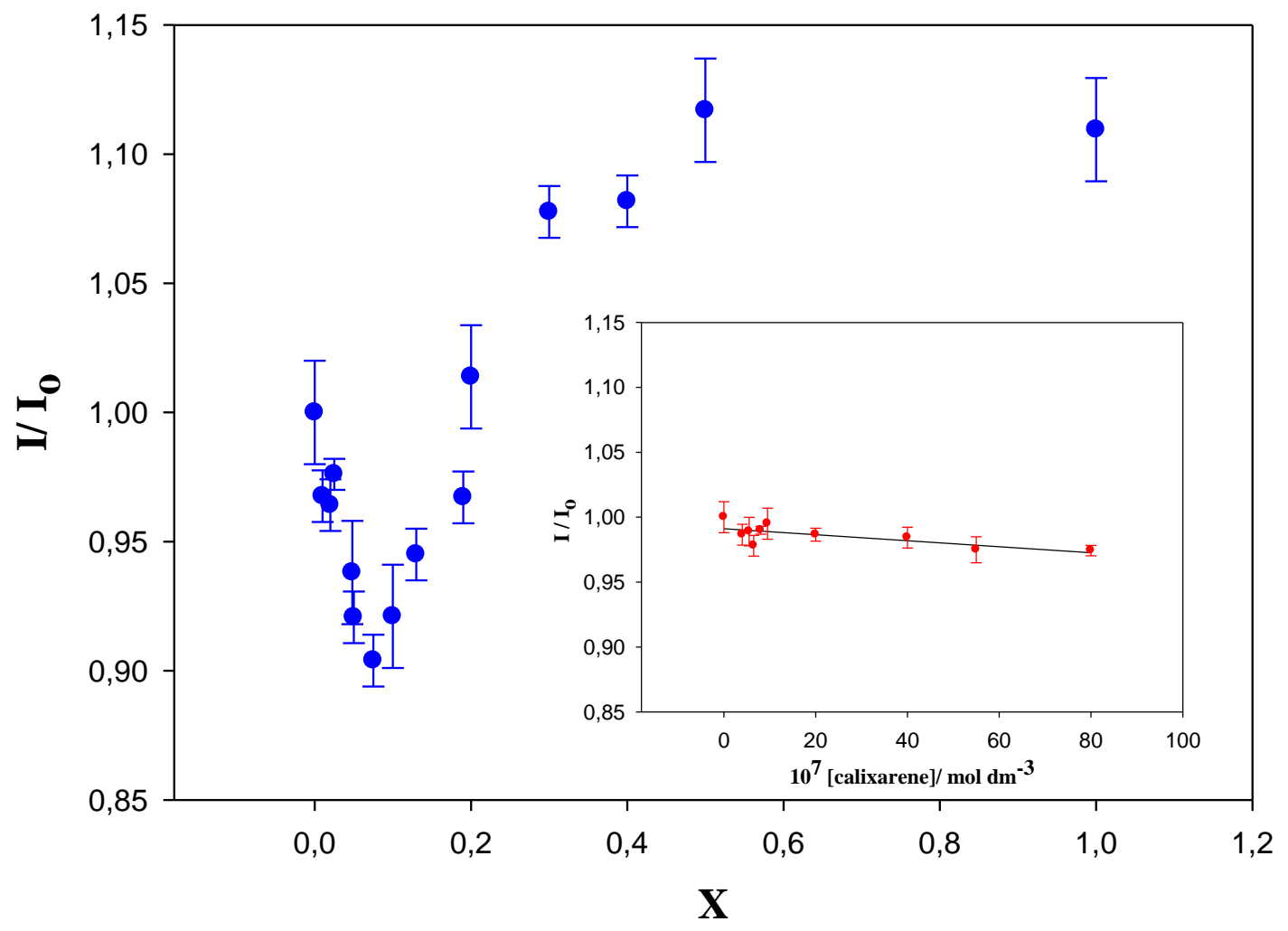


Figure 3
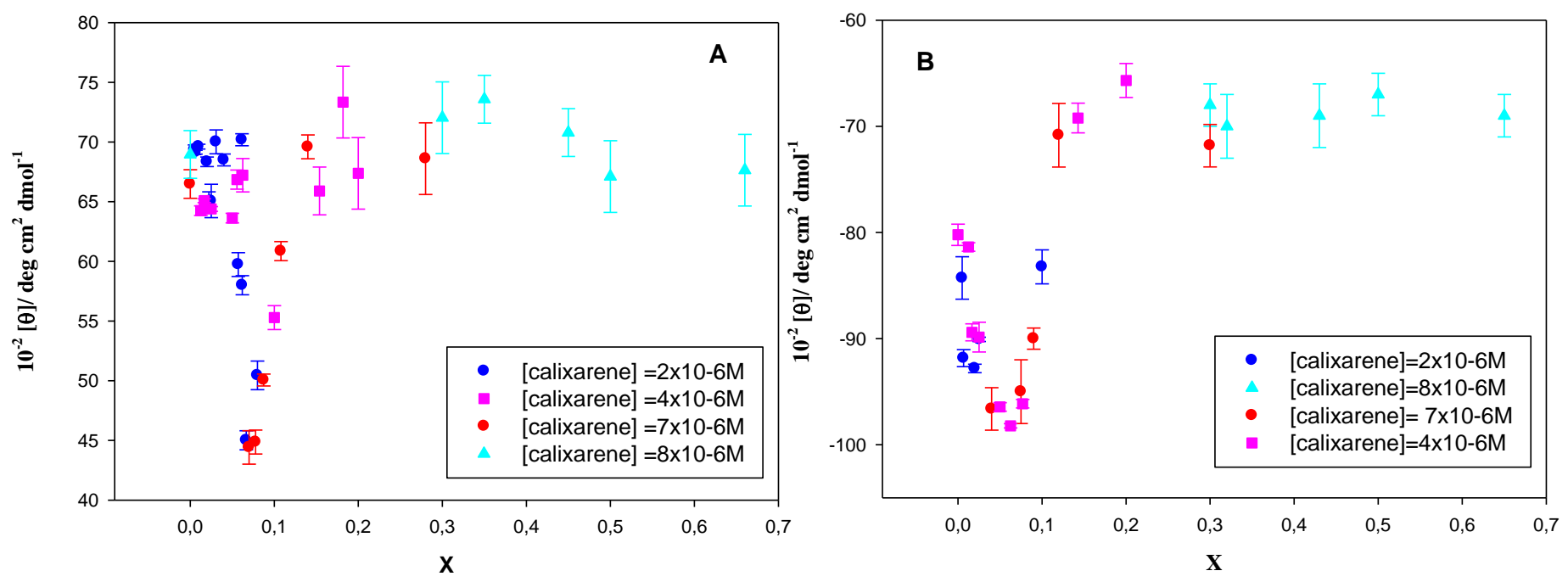

Figure 4

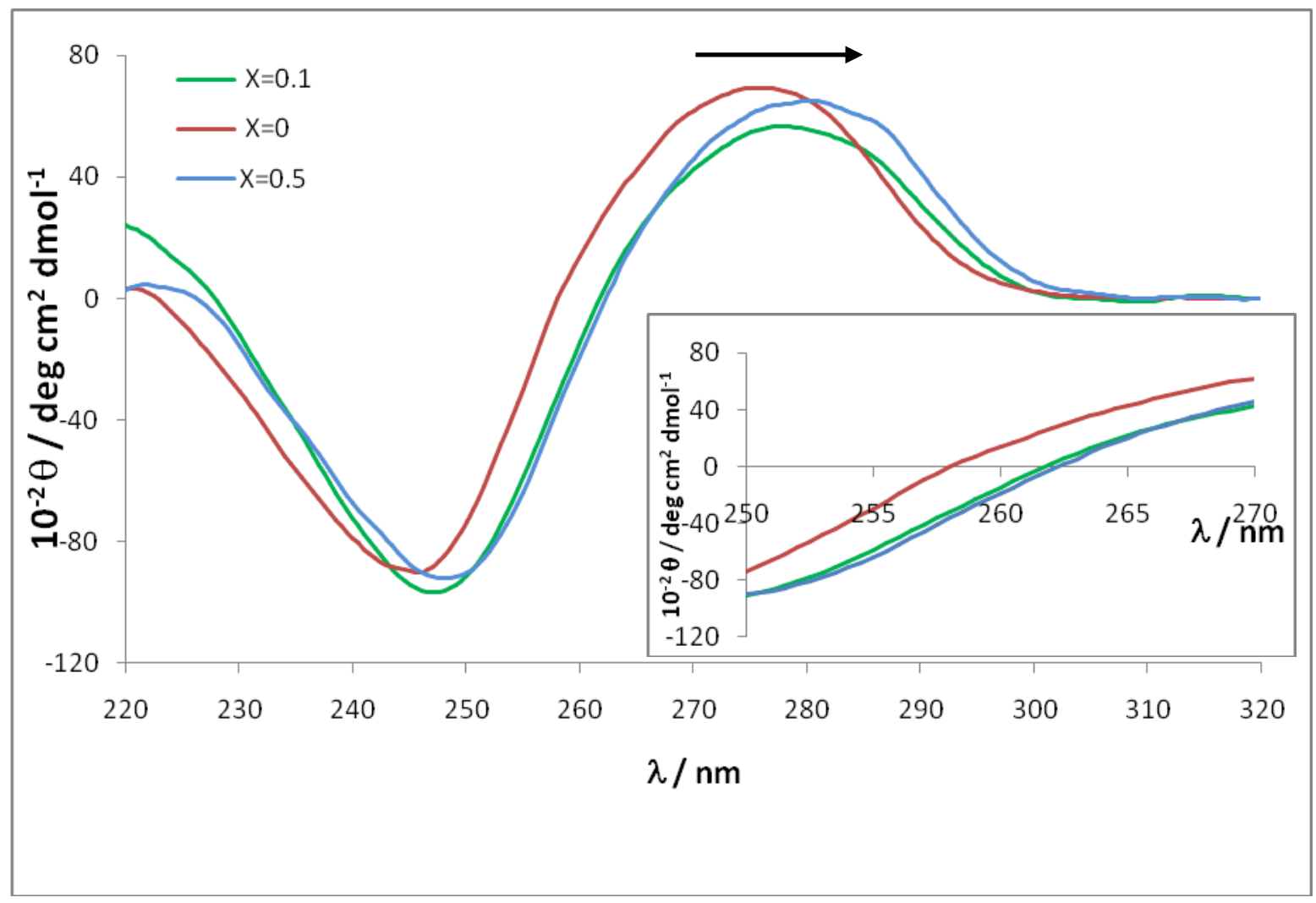


Figure 5
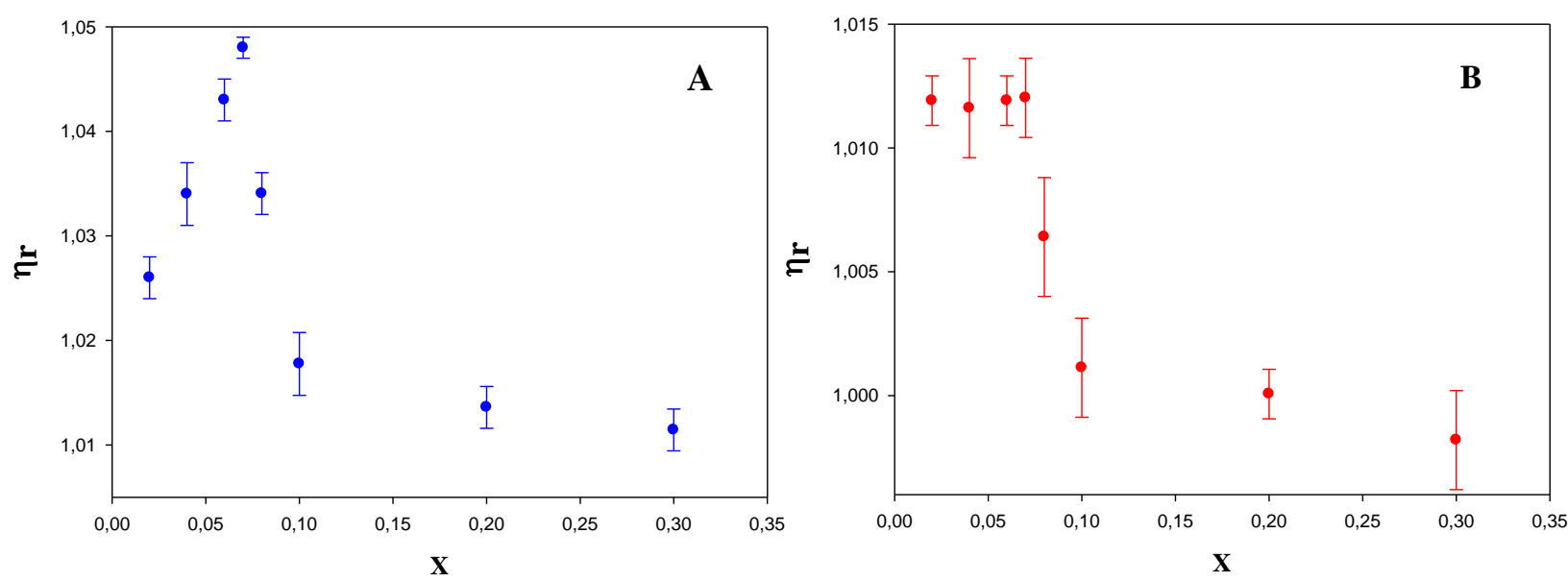

Figure 6
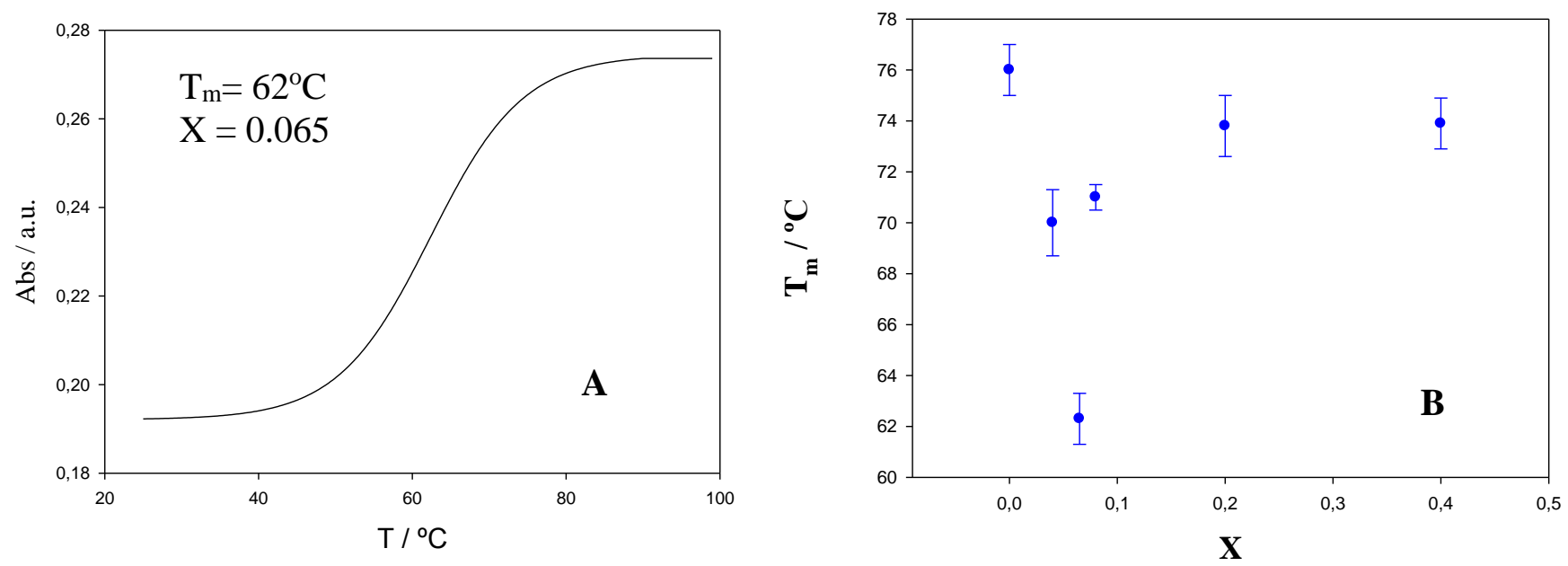
Figure 7
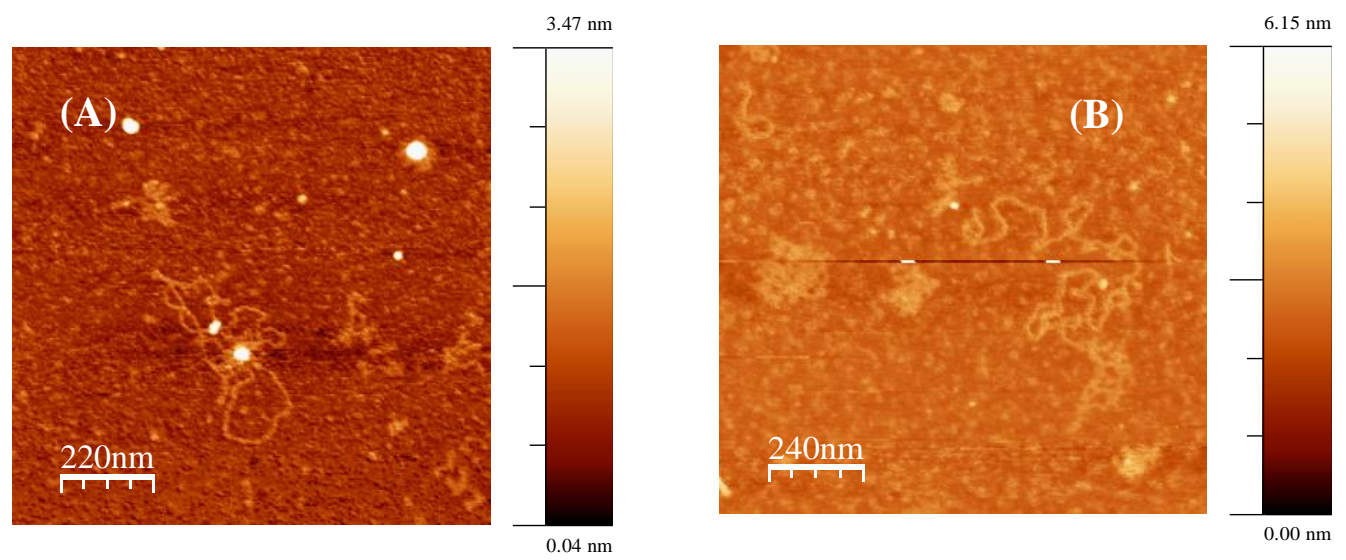

Figure 8

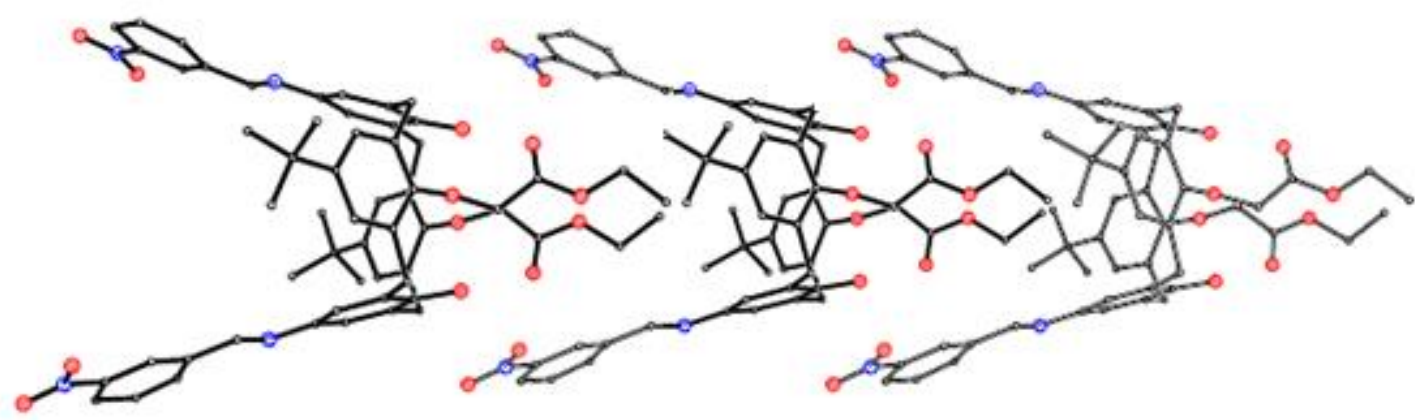

